

Original Research Article

https://doi.org/10.20546/ijcmas.2017.607.412

\title{
Molecular Characterization of Measles Virus among Children in Parts of North Western Nigeria
}

\author{
K. Abdul Fatai ${ }^{1 *}$, O.S. Olonitola ${ }^{2}$, M. Aminu ${ }^{2}$ and E.D. Jatau ${ }^{2}$ \\ ${ }^{1}$ Department of Microbiology, Kaduna State University, Kaduna, Nigeria \\ ${ }^{2}$ Department of Microbiology, Ahmadu Bello University, Zaria, Nigeria \\ *Corresponding author
}

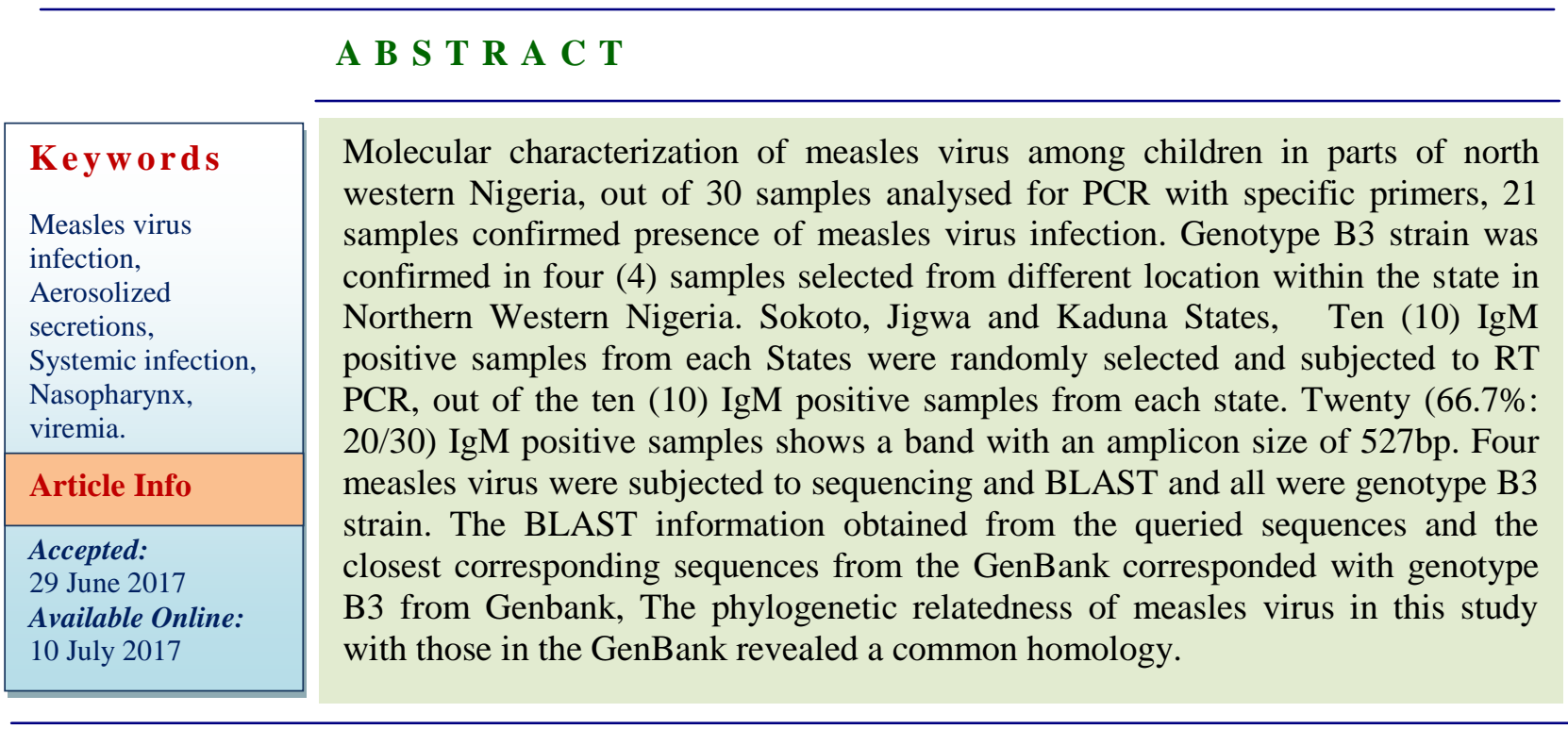

\section{Introduction}

Measles virus belonging to the genus Morbillivirus in the family

PARAMYXOVIRIDAE is an enveloped virus with a non-segmented, negative-strand RNA genome (Griffin, 2001). It is $100-200 \mathrm{~nm}$ in diameter and two membrane envelope proteins are important in pathogenesis which are the $\mathrm{F}$ (fusion) protein, which is responsible for fusion of virus and host cell membranes, viral penetration, and hemolysis, and the $\mathrm{H}$ (hemagglutinin) protein, which is responsible for adsorption of virus to cells (Bellini et al., 2005). The World Health Organization (WHO) currently recognizes 8 clades designated A, B, C, D, E, F, G, and H. Within these clades, there are 23 recognized genotypes, designated A, B1, B2, B3, C1, C2, D1, D2, D3, D4, D5, D6, D7, D8, D9, D10, E, $\mathrm{F}, \mathrm{G} 1, \mathrm{G} 2, \mathrm{G} 3, \mathrm{H} 1$, and $\mathrm{H} 2$, and one provisional genotype, d11 (WHO, 2015).

In order to infect a cell, a virus must first bind to a cellular receptor on the surface and enter the cell. The presence of such a receptor determines whether the cell is susceptible to the virus. Measles is a highly infectious disease characterized by fever, respiratory symptoms, redness of the eyes and a 
maculopapular rash. Complications are common and may be quite serious. The rash usually starts on the head and then spreads to the rest of the body. Fever can persist, reaching extremely high temperatures, rash can last for up to a week, and coughing can last about 10 days (Jawestz et al., 2011).

The causative agent of measles virus is generally transmitted by aerosolized secretions deposited on upper respiratory tract mucosal surfaces. Exposure leads to local respiratory tract replication; infection of regional lymphoid tissues then occurs followed by viremia and systemic dissemination as revealed by the characteristic skin rash. Most children recover uneventfully from the illness, but serious complications can occur, including pneumonia and involvement of the central nervous system (Parks et al., 2009). Airflow studies demonstrated that droplet nuclei generated in the examining room used by the source patient were dispersed throughout the entire office suite. Airborne spread of measles from a vigorously coughing child was the most likely mode of transmission (Bloch et al., 2005).

Measles is a systemic infection and the primary site of infection is the respiratory epithelium of the nasopharynx. Two to three days after invasion and replication in the respiratory epithelium and regional lymphnodes, a primary viremia occurs with subsequent infection of the reticuloendothelial system. Following further viral replication in regional and distal reticuloendothelial sites, a second viremia occurs 5-7 days after initial infection. During this viremia, there may be infection of the respiratory tract and other organs. Measles virus is shed from the nasopharynx beginning with the prodrome until 3-4 days after rash onset (Gerber et al., 2009). Prevention of measles infection rests on successful immunization with currently available live, attenuated vaccine. The immunity produced by the vaccine lasts many years and is probably life-long. The recommended age of administration in infant immunization programmes is 9 to 15 months. Vaccine efficacy is $85 \%$ at 9 months of age and increases to $90-95 \%$ at $12-15$ months of age. Measles virus is highly transmissible. High routine immunization coverage can reduce measles incidence but will not prevent accumulation of susceptible individuals, which can lead to outbreaks if virus is introduced into a population where the number of susceptible individual are above the critical threshold for that population (WHO, 2010).

The use of vitamin A in treatment has been investigated. A systematic review of trials into its use found no significant reduction in overall mortality, but it did reduce mortality in children aged less than two years (Souza et al., 2002).

Five out of six WHO regions have set goals to eliminate measles, and at the 63rd World Health Assembly in May 2010, delegates agreed to a global target of a $95 \%$ reduction in measles mortality by 2015 from the level seen in 2000, as well as to move towards eventual eradication. However, no specific global target date for eradication has yet been agreed (WHO, 2010).

\section{Materials and Methods}

\section{Study Area}

The study was conducted in some North Western region of Nigeria, Sokoto, Jigawa and Kaduna State.

\section{Study Population}

Children 0-12 years of age with suspected measles symptoms like, fever of $38^{0} \mathrm{C}$ or greater, cough, redness of the eyes and 
maculopapular rash, attending selected hospitals in the study area were included.

\section{Sample Size}

A convenience sampling technique was employed; therefore, 30 blood samples of children attending some selected hospital in the North western Nigeria were collected.

\section{Sample Collection and Analysis}

Blood samples were collected aseptically from each clinical case child by an experienced technician and dispensed into sterile labeled plain specimen bottles.

\section{RNA Extraction}

Total measles virus RNA from clinical samples was obtained using the QIAamp Viral RNA kit (Qiagen Hilden Germany) according to manufacturer's protocol. Blood samples from measles cases were obtained by centrifugation for 2 mins at 2300rpm. RNA was extracted from pellet using the spincolumn procedure. Two hundred microlitre $(200 \mathrm{ml})$ of each positive blood sample was transferred into a clean tube. Five hundred microlitre $(500 \mu 1)$ of lysis buffer AVL was dispensed into each clean tube and incubated at room temperature for 10 minutes. The samples were mixed by pulse - vortexing for one minute. The sample mixtures were centrifuged at 12000rpm for five minutes. The spin columns were transferred into a clean $2 \mu 1$ collection tube and the filtration was discarded. Five hundred microlitre $(500 \mathrm{ml})$ of wash buffer AWI was added to each spin column and centrifuge at $12000 \mathrm{rpm}$ for two minutes. The filtrate was discarded. The empty spin columns were centrifuged at 10000rpm for two minutes. The spin columns were transferred into new clean tubes and $60 \mu 1$ of elution buffer AVE was added into each spin column and allowed to stand at room temperature $\left(25^{\circ} \mathrm{C}\right)$ for 2 minutes. Centrifugation was done at $10000 \mathrm{rpm}$ for two minutes to elute the RNA from the spin columns into the tube. A double elution was done by adding $100 \mathrm{ml}$ of elution buffer AVE into each spin column and centrifuged after two minutes at $10000 \mathrm{rpm}$ for two minutes. RNA samples were stored at $-80^{\circ} \mathrm{C}$ until required for use.

\section{RT-PCR Amplification}

Specific cDNA of Measles Virus nucleoprotein was synthesized by a reverse transcription using Superscript III Reverse Transcriptase (Invitrogen, Merelbeke, Belgium) and random hexamers (Invitrogen). The Measles Virus cDNA was amplified by nested PCR using primers (Table 1) MN5 ( 5' - GCC ATG GGA GTA GGA GTG GAA C 3') and MN6 ( 5' - CTG GCG GCT GTG TGG ACC TG - 3' ) for the first round and primers Nfla ( 5' - CGG GCA AGA GAT GGT AAG GAG GTC AG - 3') and Nr7a (5'AGG GTA GGC GGA TGT TGT TCT GG3 ') for the second round. Both PCRs were performed in a total volume of $25 \mu \mathrm{L}$ that contained $1.8 \mathrm{mmol} / \mathrm{L} \mathrm{MgCl}_{2}, 1 \times$ PCR buffer, $0.2 \mathrm{mmol} / \mathrm{L}$ dNTPs, $0.5 \mathrm{U}$ Platinum Taq (Invitrogen), and $0.8 \mu \mathrm{mol} / \mathrm{L}$ forward and reverse primer (Eurogentec, Seraing, Belgium). One microliter of cDNA or $5 \mu \mathrm{L}$ of first-round product (diluted 50x in water) was added as template. Cycling conditions was denatured at $94^{\circ} \mathrm{C}$ for $2 \mathrm{~min} ; 35$ (first round) or 30 (second round) cycles of amplification at $94^{\circ} \mathrm{C}$ for $30 \mathrm{sec}, 55^{\circ} \mathrm{C}$ (first round) or $58^{\circ} \mathrm{C}$ second round) for $1 \mathrm{~min}$, and $72^{\circ} \mathrm{C}$ for $1 \mathrm{~min}$; and a final extension at $72^{\circ} \mathrm{C}$ for $5 \mathrm{~min}$

\section{Detection and Identification of the Amplified PCR Products}

Agarose gel of $1 \%$ concentration was prepared by weighing one gram of agarose in a conical flask and adding $100 \mathrm{ml}$ of $1 \mathrm{x}$ TAE 
buffer (Tris Acetate EDTA). The agarose was solubilized by heating in a microwave oven for two minutes. The solubilized agarose was allowed to cool to $40^{\circ} \mathrm{c}$ and $5 \mathrm{ml}$ of ethidium bromide was added. The gel was poured into the gel tray with the combs in place was left to solidify for about 50minutes. Electrophoresis tank was filled with the running buffer (Tris Acetate EDTA) and the gel slab was totally submerged in the buffer at a level not more than two millimeters above the gel. The combs were gently removed to give well formed wells. About $20 \mathrm{ml}$ of each amplified PCR product was loaded into respective wells and 100 volts was applied for 30 minutes using Bio - Rad power pack (powerpac TM HC). The power supply was turned off after 30 minutes. The gel was removed and examined using Bio - Rad Gel Doc Molecular Imager System (Gel Doc TM XRT). The basepair of the amplicon was determined using the standard (100bp DNA ladder).

\section{Cycle Sequencing}

Sequencing reaction were Prepare in a $0.2 \mathrm{~mL}$ thin-wall tube with 2 tubes per template DNA for a forward sequencing primer and a reverse sequencing primer reaction. All reagents were kept on ice box while preparing the sequencing reactions, $8 \mu \mathrm{l}$ of sterile water and $2 \mu \mathrm{l}$ of diluted plasmid DNA (at 100 ng/ul) were added to each sequencing tube. The tubes were spanned briefly. The plasmid water was preheat and mixed at $96 \mathrm{C}$ for 1 min in the thermo cycler and then cools on ice box. $8 \mu$ I DTCS Quick Start Master was added and Mixed to each tube followed by 2 $\mu 1$ of $\mathrm{T}-7$ forward sequencing primer added to one of the tubes for a template and $2 \mu \mathrm{l}$ of SP6 reverse sequencing primer was added to the other tube for a template.

The reaction components were mixed thoroughly. The liquid at the bottom of the tube was consolidated and briefly centrifuging before thermo cycler with the following conditions; $96^{\circ} \mathrm{C}$ for 20 seconds, $50^{\circ} \mathrm{C}$ for 20 seconds and $60^{\circ} \mathrm{C}$ for 4 minutes

\section{Cycle Sequencing Clean up}

Nested PCR products were purified by using the Jetquick PCR product Purification Spin Kit (Genomed, Lohne, Germany). Twentyfive cycles of cycle sequencing (2-min elongation) were performed by using a BigDye Terminator version 6.1 Cycle Sequencing kit (Applied Biosystems, Nieuwerkerk, the Netherlands) with Nf1a or $\mathrm{Nr} 7 \mathrm{a}$ primers $(0.5 \mu \mathrm{mol} / \mathrm{L})$ and $10 \mathrm{ng}$ of purified PCR product. The product was sequenced for measles virus genotyping using an ABI 3130 Genetic Analyzer (Applied Biosystems). Phylogenetic trees were constructed by using the neighbor-joining method (Kimura 2-parameter) and MEGA7 version software

\section{Results and Discussion}

Ten (10) samples from each States were subjected to RT- PCR. 10 samples selected from Sokoto State, 6 samples selected from Jigawa State and 4 samples selected from Kaduna State showed bands for measles virus. (Plate I, II, and III). Four (4) measles virus isolate (products of RT-PCR) from the studied states were sequenced, 2, 1 and 1 isolate from Sokoto, Jigawa and Kaduna State respectively. All the 4 sequenced were genotype B3 strain. The distribution of measles virus in the respective states in the study area is presented in tables 1, 2, 3 and 4 .

The BLAST information obtained from the Query sequences and the closest corresponding sequences from the genbank revealed that samples S3, S4, J21 and K24 correspond with genotype B3 sequences from the genbank. This is presented in table 5 and 6. 
Table.1 Detection of measles virus from blood samples in Sokoto state

\begin{tabular}{lcc}
\hline S/N & Sample Number & RT-PCR \\
\hline 1 & S3 & + \\
2 & S4 & + \\
3 & S19 & + \\
4 & S24 & + \\
5 & S25 & + \\
6 & S26 & + \\
7 & S50 & + \\
8 & S51 & + \\
9 & S70 & + \\
10 & S78 & + \\
\hline
\end{tabular}

Key- S = sample number from sokoto state, $+=$ positive product of $\mathrm{RT}$ PCR, $-=$ negative product of RT PCR

Table.2 Detection of measles from blood samples in Jigawa State

\begin{tabular}{lcc}
\hline S/N & Sample Number & RT- PCR \\
\hline 1 & J5 & - \\
2 & J10 & + \\
3 & J21 & + \\
4 & J29 & - \\
5 & J66 & - \\
6 & J76 & + \\
7 & J82 & + \\
8 & J92 & + \\
9 & J98 & + \\
10 & J102 & - \\
\hline
\end{tabular}

Key: J=Samples in Jigawa State

Table.3 Detection of measles virus from blood samples in Kaduna state

\begin{tabular}{lcc}
\hline S/N & Sample Number & RT- PCR \\
\hline 1 & K2 & - \\
2 & K3 & - \\
3 & K8 & + \\
4 & K24 & + \\
5 & K28 & - \\
6 & K36 & - \\
7 & K40 & - \\
8 & K43 & + \\
9 & K63 & - \\
10 & K76 & + \\
\hline
\end{tabular}

Key: $\mathrm{K}=$ Samples Collected from Kaduna 
Table.4 Percentages prevalence of measles virus in the north western Nigeria

\begin{tabular}{llc}
\hline State & n & \% occurrence \\
\hline Sokoto & 10 & $10(10)$ \\
Jigawa & 10 & $6(60)$ \\
Kaduna & 10 & $4(40)$ \\
\hline Total & $\mathbf{3 0}$ & $\mathbf{2 0}(\mathbf{6 6 . 7})$ \\
\hline
\end{tabular}

Key: $n=$ Number of IgM Positive Sample; Number in Parentheses= Percentage $\%=$ Percentage

Table.5 Cycle sequencing products

\begin{tabular}{ll}
\hline Location & MV Genotype B3 Sequencing \\
\hline SOK3 & TAGGGGTGTCCGTGTCTGAGTCTTGTCTTAGATTCCTGCCATGGCTTGCAGCCTGA \\
& GCAGGGCATCGGCTGACCTTCGACTGTCCTGCGGATCTTGGCTGAACTCCGATGC \\
& AGTGTCAATGTCTAGGGGTGTGCCGGTTGGAGGATGGGCAGCTCTCGCATCACTT \\
& GCTCTGCTGGGCTCGGTTCTCTGTGGCTCTCCCCGGCTTCTCCTCGGTTCTGTTTG \\
& ACCCTCCTGTCCTCCTTAACCCCCAATCTCGGCAGCTCATTCTCACTTTGATCACC \\
& GTGTAGAAATGACACTTGGGCTTGTCTGGGTCCAACTGATCTGCTGATCCTGTCCT \\
& CAGTAGTATGCATTGCAATCTCTGAAACAAGCCTTGCATCCTCGGCAGTTATACCG \\
& AGTTCAGATGCCAATGTGGAACTGACCTTTCCAGCTGACCTCCTTACCATC \\
& \\
SOK4 & \\
& CATTGTACACTCTAGGGGTGTCCGTGTCTGAGTCTTGTCTTCCGAGATTCCTGCCA \\
& TGGCTTGCAGCCTAAGCAGGGCATCGGCTGACCTTCGACTGTCCTGCGGATCTTG \\
& GCTGAACTCCGATGCAGTGTCAATGTCTAGGGGTGTGCCGGTTGGAGGATGGGCA \\
& GCTCTCGCATCACTTGCTCTGTGGGCTCGGTTTCTCTGTGGCTCTCCCGGGCTTCTC \\
& CTCGGTTCTGTTTGACCCTCCTGTCCTCCTTACCCCCCAATCTCGGTAGCTCATTCT \\
& CACTTTGATCACCGTGTAGAAATGACCTTGGGCTTGTCTGGGTCCAACTGCTCTGC \\
& TGATCCTGTCCTCAGAGTATGCATTGCAATCTCTGAAACAAGCCTTGCATCCTCGG \\
& CAGTATACCGAGTTTCAGATGCCAATGTGGAATGACCTTTCCAGCTGACCT
\end{tabular}

JG21 TTGTACACTCTAGGGGTGTCCGTGTCTGAGTCTTGTTCTTCCGAGATTCCTGCCAT GGCTTGCAGCCTAAGCAGGGCATCGGCTGACCTTCGACTGTCCTGCGGATCTTGG CTGAACTCCGATGCAGTGTCAATGTCTAGGGGTGTGCCGGTTGGAGGATGGGCAG CTCTCGCATCACTTGCTCTGCTGGGCTCGGTTTCTCTGTGGCTCTCCCGGGCTTCTC CTCGGTTCTGTTTGACCCTCCTGTCCTCCTTACCCCCCAATCTCGGCAGCTCATTCT CACTTTGATCACCGTGTAGAAATGACACTTGGGCTTGTCTGGGTCCAACTGATCTG CTGATCCTGTCCTCAGTAGTATGCATTGCAATCTCTGAAACAAGCCTTGCATCCTC GGCAGTTATACCGAGTTCAGATGCCAATGTGGAACTGACCTTTC

KD24 CTCTAGGGGTGTCCGTGTCTGAGTCTTGTTCTTCCGAGATTCCTGCCATGGCTTGC AGCCTAAGCAGGGCATCGGCTGACCTTCGACTGTC

KEY: Sok3= Sokoto sample number 3, Sokoto4 = Sokoto sample number 4, JG21 = Jigawa sample number 21, KD24 = Kaduna sample number 24 


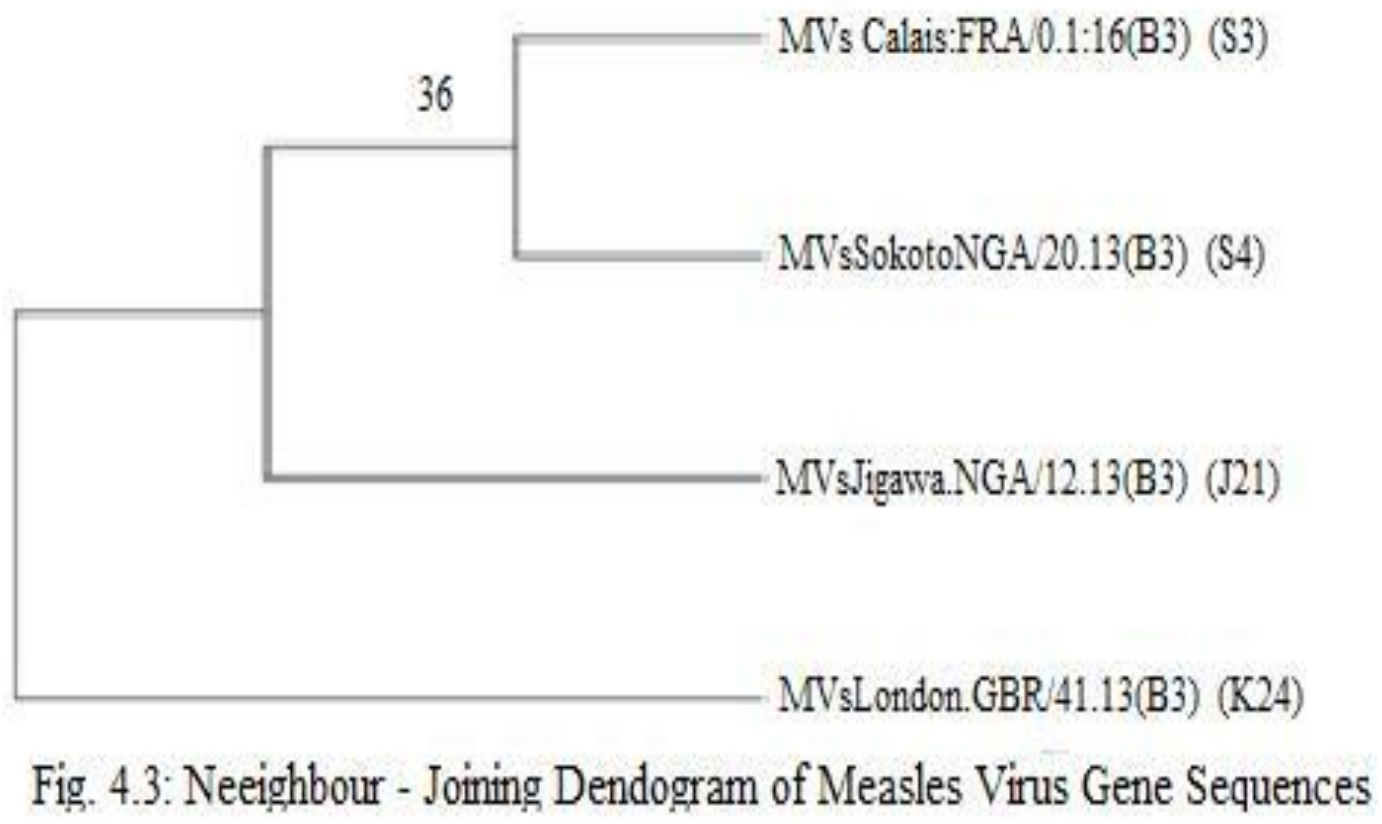

Plate.1 Agarose Gel Electrophoresis of RT-PCR products of Measles virus IgM Positive Samples from Sokoto States

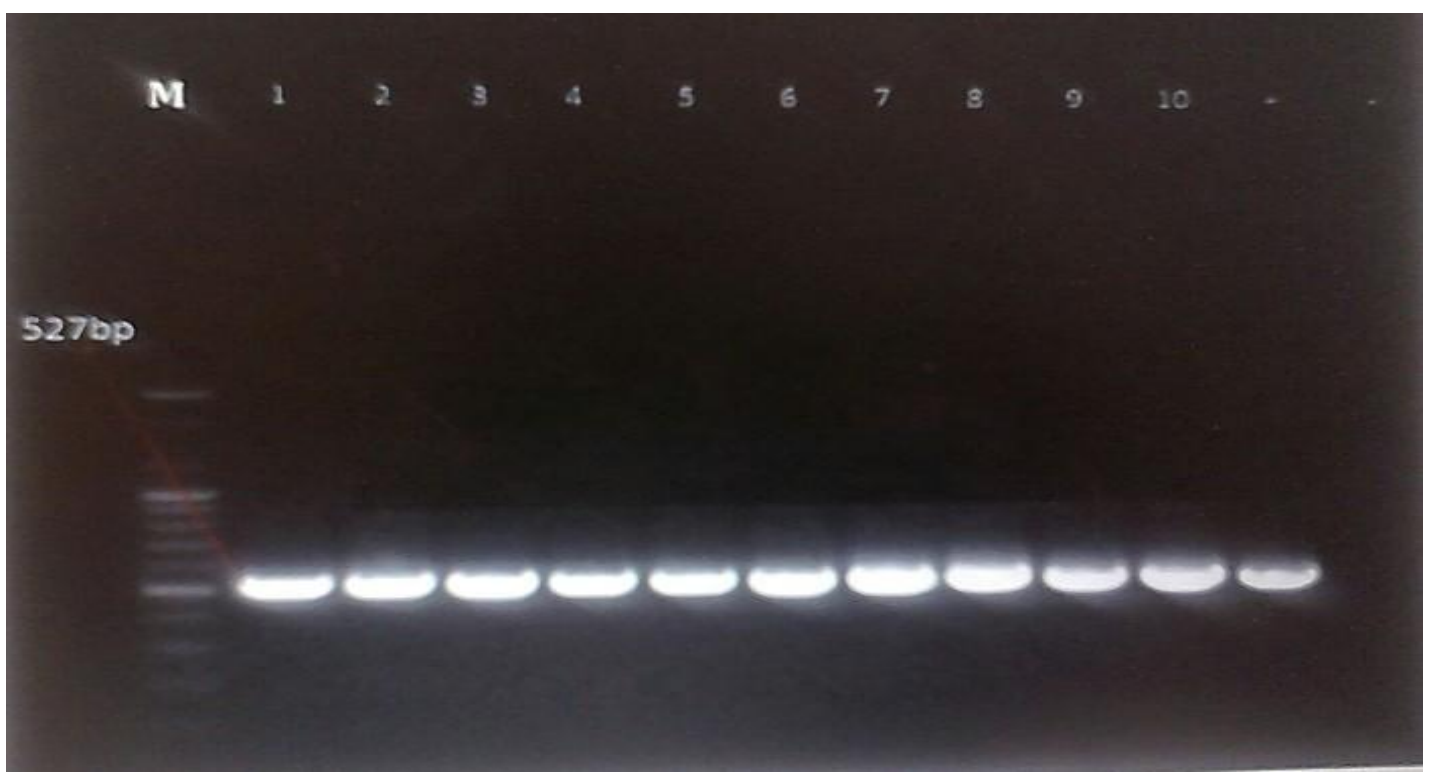

Key: Lane M 100bp DNA Ladder; Lane 1- 10 amplicons products; Lane + = Positive Control; Lane - = Negative Control 
Plate.2 Agarose Gel Electrophoresis of RT-PCR products of Measles virus IgM Positive Samples from Jigawa and Kaduna States



Key: $\quad$ Lane M 100bp DNA Ladder; Lane 11, 14, 15, 20, 21, 22 and 25 were negative; Lane 12, 13, 16, 17, 18, 19, 23 and 24 shows amplicons of Measles virus; Lane - = Negative Control

Table.6 Closest Affiliates of Measles Virus Sequence Obtained Compared with those from GenBank

\begin{tabular}{lcccccc}
\hline Seq & Accession No & Max Score & $\begin{array}{c}\text { Total } \\
\text { Score }\end{array}$ & $\begin{array}{c}\text { Query } \\
\text { length }\end{array}$ & E - value & Identity \\
\hline S3 & KX838946.2 & 764 & 764 & 442 & 0.0 & $98 \%$ \\
S4 & KX949610.1 & 722 & 722 & 443 & 0.0 & $98 \%$ \\
J21 & KX949603.1 & 773 & 773 & 436 & 0.0 & $99 \%$ \\
K24 & KT732217.1 & 785 & 785 & 450 & 0.0 & $99 \%$ \\
\hline
\end{tabular}

The query sequences covers almost $100 \%$

Plate.3 Agarose Gel Electrophoresis of RT-PCR products of Measles virus IgM Positive Samples from Kaduna State



Key:

Lane M 100bp DNA Ladder; Lane 26, 27 and 29 were negative; Lane 28 and 30 shows amplicons of Measles virus; Lane $+=$ Positive Control; Lane $-=$ Negative Control 
Phylogenic tree were prepared using Mega 7 version software and the neighbor - joining method with 1000 bootstrap replicates. Sequences from North Western Nigeria Measles virus strains ware compared with the sequences of B3 genotype on Genbank. This is presented in figure 3 .

Twenty $(66.7 \%)$ of the 30 IgM positive samples were positive for measles virus gene. This agree with the finding of Mohammoud et al., (2013), Zhang et al., (2012), who reported the incidences of measles virus in Africa and China respectively. This could be due to long period of sampling before analysis because the virus may not be able to survive a long period of time before screening, but the $\operatorname{IgM}$ antibody will still be present in the sample no matter the period it stayed before screening. This result also shows that RT - PCR is a sensitive and specific assay for detecting measles virus RNA in a variety of clinical samples. This agrees with the finding of Jangu et al., (1995) who detected measles virus RNA in clinical samples using RT-PCR. The entire four measles virus were subjected to sequencing and BLAST. All the four were genotype B3 strain, this agrees with the finding of Michaela et al., (2005) who reported that Genotype B3 was first detected in 1993 in Gambia but have subsequently been detected in cases from Cameroon, and Central Africa and has been imported into numerous countries including France, Germany and the USA. Genotype B3 is clearly the endemic genotype in most parts of the African Continent where it is widely distributed (WHO, 2012).

The BLAST information obtained from the queried sequences and the closest corresponding sequences from the GenBank revealed that samples S3 and S4 from Sokoto State corresponded with genotype B3 from Genbank, Sample J21 and K24 from Jigawa and Kaduna State respectively also corresponded with B3 strain in the GenBank.

The phylogenetic relatedness of measles virus in this study with those in the GenBank revealed a common homology. Measles virus S3 and S4 on the same leavenode were genetically highly related to one another and related to those gotten from Calais (FRA/01:16) and Sokoto (NGA/20.13), but vary with those on a neighbouring clade positions. Measles virus $\mathrm{J} 21$ is genetically closely related to Measles virus S4 on the neighboring leave node while Measles virus K24 is genetically closely related to Measles virus $\mathrm{J} 21$ on the neighboring clade position. This could be due to evolutionary relatedness, this could be that, they all emolliated from the same ancestor.

In conclusion, the measles virus strain detected in this study by sequencing and phylogenetic analysis was genotype B3 Strain and the phylogenetic analyses in this study revealed a close relationship of the querry sequences with the one obtained from France, Newcastle, London and North central part of Nigeria (Niger).

\section{Acknowledgement}

We wish to express our deep sense of gratitude to the management of Sokoto, Jigawa, and Kaduna State Ministry of health for giving us the ethical approval to carry out this research. We also appreciate the support rendered by staff at various facilities.

\section{References}

Adetunji, O.O., Olusola, E.P., Ferdinad, F.F., Olorunyomi, O.S., Idowu, J.V., and Ademola O.G. 2007. Measles among hospitalized Nigerian Children. The Int. J. Paediatrics and Neonatol., 7(1): 88-102.

Adetunji, O.O., Olusola, E.P., Ferdinad, F.F., Olorunyomi, O.S., Idowu, J.V., and Ademola, O.G. 2010. Measles Epidemiology 
in Nigerian Children. The Int. J. Pediatrics and Neonatol., 8(2): 99-108.

Ahmadu, B.U., Mava, Y., Ambe, J.P., Abdallahi, J.A., and Ovansa, E.O 2013. Predicting changing measles epidemiology in an urban West African Population. Annals of Trop. Med. Public Health, 6: 179 - 182.

Ahmed, P.A., Babaniyi, I.B., Otuneye, A.T. 2010. "A review of childhood apoptosis of uninfected lymphocytes in acute measles patients. Arch. Bullet World Health organization, 70(4): 457-460.

Akanmuzzaman, S.M., Cutts, F.T., Hossain, M.J. 2010. Measles Vaccine Effectiveness and risk factor for measles in Dhaka, Bangladesh. Bull. World Health Organization, 80(10): $776-782$.

Aumatell, C.M., Ramon - Torrell, J.M., Rituerto, A.C Navarro, M.B Gamboa Mdel, R.D., Rodriguez, S.L. 2013. Measles in Bolivia a honeymoon period Vaccine, 31: 2097 - 2012.

Bellini, W.J., Englund, G., Rozenblatt, S., Arnheiter, H. \& Richardson, C.D. 2005. Measles virus $\mathrm{P}$ gene codes for two proteins. J. Virol., 53: 908-919.

Danet, C., Fermon, F. 2013. Management of a Diseases and immunity, J. Med., 3(6): 112-6.

Farina, C., Theil, D., Semlinger, B., Hohlfeld, R. \& Meinl, E. 2004. Distinct responses of monocytes to Toll-like receptor ligands and inflammatory cytokines. Int. J. Immunol., 16: 799-809.

Fetuga, M.B., Njokanma, O.F., Ogunfowora, O.B., Runsewe-Abiodun. 2007. Global measles control and elimination. Weekly Epidemiological Reports

Holmes, S.J Morrow, AL., and Piekering, L.K. 1996. Childcare practices: Effects of social change on the epidemiology of infectious diseases and antibodies resistances. $J$. Epidemiologic Rev., 18(1): 10 - 27.

Ismail, I., Latif, Mehdi, S.H., Al-Zuheiry, Nadhim, G.H., Noaman. 2014. SeroEpidemiological Study of Outbreak of Measles among Children in Diyala. J. Pure Sci., 6(3): 236-246.

James, L., Goodson Balcha, G., Masresha Kathleen Wannemuehler Amra Uzicanin Stephen Cochi. 2011. Changing Epidemiology of Measles in Africa. J. Infect. Dis., (6): 205-214.
Manirakiza, A., Kipela, J.M., Sosler, S., Daba, R.M and Vasilache, I.G. 2012. Serpervalence of Measles and Natural rubella antibodies amonge children in Bangui, Central Africa Republic. J. Public Health Sci., 11: 1471 2458.

Muhammed, A, and Danish. 2014. Relationship between child immunization and household soico - demographic characteristics in Pakistan. J. Humanities and Social Sci., 6(7): $90-102$.

Muhammed, A. and Danish. 2011. Relationship between child immunization and household soico - demographic characteristics in Pakistan. J. Humanities and Social Sci., 4(7): $82-90$.

Nguku, P., Mohammed, A., Abanida, E., Sabitu, K. 2012. Evaluation of measles case-based surveillance system in Nigeria. J. Virol., 6(3): 271-282.

Nichols, K.E., Ma, C.S., Cannons, J.L., Schwartzberg, P.L. \& Tangye, S.G. 2005. Molecular and cellular pathogenesis of Xlinked lymphoproliferative disease. $J$. Immunol. Rev., 203: 180-199.

Nishoe, G.M., McAnerey, J.M., Archer, B.N., Smit, S.B., Harris, B.N., Stefano, T., Mashele M., Singh B., Thomas J., Cengimbo A., Blumberg L.H., Puren A., Moyes J., Heever J., Schoub B.D and Cohen C. 2013. Measles Outbreak in South Africa Epidemiology of Laboratory - Confirmed Measles Cases and Assessment of Intervention 2009 - 2011. Supplementary one, 8(2): 1371.

Odoemele, C.F., Ukwandu, N.C., Adu, F.D., Nmorsi, O.P., Anyanwu, L.C. 2008. The nomenclature for describing the genetic characteristics of wild-type measles virus. $J$. Infect. Dis., 3(6): 201-215.

Okada, H., Kobune, F., Sato, T.A., Onyiruika, A.N. 2012. Prevalence of maternal antibody to measles virus throughout rates to measles vaccine among children in Nigeria, J. Infect. Dis., 13(4): 413-416.

Oyedele, O.O., Odemuyiwa, S.O., Ammerlaan, W., C.P., Adu F.D. 2005. Passive Immunity to measles in the breast milk and cord blood of some Nigerian subjects J. Virol., 77: 7635 -44 .

Patel, P.K., Al - Awaidy, S.T., Bawikar, S., and Al - Mahroqi, S. 2009. Measles 
epidemiology and its implications for a vaccination programme in Oman. Eastern Mediterium Health J., 4(3): 5 - 8 .

Rota, J.S., Wang, Z.D., Rota, P.A. \& Bellini, W.J. 2009. seroepidemiology and decay rate of vaccine-induced Infections, 6(8) 88-96.

Shaffer, J.A., Bellini, W.J. \& Rota, P.A. 2009. The $\mathrm{C}$ protein of measles virus inhibits the type I interferon response. J. Virol., 3(15): 389-397.

Wairagkar, N., Chowdhury, D., Vaidya, S., Sikchi, S., Shaikh, N., Hungund, L. 2011. Molecular epidemiology of measles in India, 2005-2010. J. Infect. Dis., Suppl (1): 40313.

Wichmann, L.E., Ukwandu, N.C., Thomas, J., Anyanwu, L.C. 2009. Investigation of large outbreak of measles in Germany, a shift in the distribution of cases to older, previously unvaccinated children within the age bracket of 10 to 14 years. J. Infect. Dis., (8): 185199.

World Health Organization Fact sheet $N^{\circ} 286$. Retrieved June 28, 2009. Updated February 2015 membrane fusion by paramyxo viruses: studies on the site of action.

World Health Organization. 2010. Expanded programme on immunization standardization progress towards Measles Outbreak.

World Health Organization. 2013. Expanded programme on immunization standardization progress towards Measles Outbreak.

World Health Organization. 2014. Expanded programme on immunization standardization progress towards Measles Outbreak.

\section{How to cite this article:}

Abdul Fatai, K., O.S. Olonitola, M. Aminu and Jatau, E.D. 2017. Molecular Characterization of Measles Virus among Children in Parts of North Western Nigeria. Int.J.Curr.Microbiol.App.Sci. 6(7): 3981-3991. doi: https://doi.org/10.20546/ijcmas.2017.607.412 